\title{
An investigation into the roles of chlorides and sulphate salts on the performance of low-salinity injection in sandstone reservoirs: experimental approach
}

\author{
Athari Al-Otaibi ${ }^{1,2}$ \\ Received: 11 May 2020 / Accepted: 30 July 2020 / Published online: 11 August 2020 \\ (c) The Author(s) 2020
}

\begin{abstract}
Numerous studies have been carried out to ascertain the mechanisms of low-salinity and smart water flooding technique for improved oil recovery. Focus was often on brine composition and, specifically, the cationic content in sandstone reservoirs. Given the importance of the salt composition and concentration, tweaking the active ions which are responsible for the fluids-rock equilibrium will bring into effect numerous mechanisms of displacement which have been extensively debated. This experimental study, however, was carried out to evaluate the extent of the roles of chloride- and sulphate-based brines in improved oil recovery. To carry this out, 70,000 ppm sulphates- and chloride-based brines were prepared to simulate formation water and $5000 \mathrm{ppm}$ brines of the same species as low-salinity displacement fluids. Core flooding process was used to simulate the displacement of oil by using four (4) native sandstones core samples, obtained from Burgan oil field in Kuwait, at operating conditions of $1500 \mathrm{psig}$ and $50^{\circ} \mathrm{C}$. The core samples were injected with $70,000 \mathrm{ppm}$ chloride and sulphates and subsequently flooded with the $5000 \mathrm{ppm}$ counterparts in a forced imbibition process. Separate evaluations of chloride- and sulphate-based brines were carried out to investigate the displacement efficiencies of each brine species. The results showed that in both high- and low-salinity displacement tests, the $\mathrm{SO}_{4}$ brine presented better recovery of up to $89 \%$ of the initial oil saturation (Soi). Several mechanisms of displacement were observed to be responsible for improved recovery during $\mathrm{SO}_{4}$ brine displacement. IFT measurement experiments also confirmed that there was reduction in IFT at test conditions between $\mathrm{SO}_{4}$ brine and oil and visual inspection of the effluent showed a degree emulsification of oil and brines. Changes in $\mathrm{pH}$ were observed in the low-salinity flooding, and negligible changes were noticed in the high-salinity floods. These results provide an insight into the roles of chloride and sulphate ions in the design of smart "designer" water and low-salinity injection scenarios.
\end{abstract}

Keywords Low-salinity flooding $\cdot$ Chloride brines $\cdot$ Interfacial tension $\cdot$ Displacement $\cdot$ Sandstones

$\begin{array}{ll}\text { Abbreviations } \\ \mathrm{Cl} & \text { Chloride } \\ \mathrm{dP} & \text { Differential pressure (psig) } \\ \text { EDX } & \text { Energy-dispersive X-ray diffraction } \\ \text { EOR } & \text { Enhanced oil recovery } \\ \mathrm{IFT} & \text { Interfacial tension } \\ \text { LSF } & \text { Low-salinity flooding } \\ \text { MIE } & \text { Multicomponent ion exchange }\end{array}$

Athari Al-Otaibi

a.al-otaibi@edu.salford.ac.uk

1 Department of Petroleum and Gas Engineering, School of Science Engineering and Environment, The University of Salford, Manchester, The Crescent, Salford M4 5WT, UK

2 Kuwait Oil Company (KOC), Ahmadi, Kuwait

$\begin{array}{ll}\text { OOIP } & \text { Oil originally in place } \\ \text { ppm } & \text { Parts per million } \\ \mathrm{PV} & \text { Pore volumes } \\ \mathrm{Soi} & \text { Initial oil saturation } \\ \mathrm{Swi} & \text { Initial water saturation } \\ \mathrm{SO}_{4} & \text { Sulphate } \\ \mathrm{TDS} & \text { Total dissolved solids } \\ \mathrm{XRD} & \text { X-ray diffraction }\end{array}$

\section{Introduction}

Water flooding is a secondary recovery method which has been in practice for decades as a means to increase the reservoir pressure and subsequently improve oil recovery without formation damage (Aminian and ZareNezhad

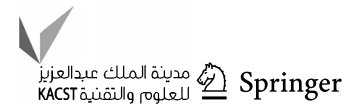


2019). That, alone, cannot provide substantially oil recovery from the pore matrix of reservoir, and as such, enhanced oil recovery (EOR) or tertiary recovery processes are employed, and their mechanics become considerably important. Several oil recovery methods have been developed and adopted, and researches into more innovative techniques are ongoing to improve oil recovery. Conventionally, oil is produced from primary recovery using the natural drive mechanism. When this energy depletes, only about $20-30 \%$ of the original oil in place (OOIP) may have been recovered (Sino Australia Oil \& Gas Pty Limited 2013) and optimisation of the production process helps in substantial recovery of the residual oil after primary production.

Typically, waterflooding entails the injection of formation water into the surrounding aquifer flanking the oil zone to improve the mobility of the oil by re-pressurising the oil reservoir, thereby imparting additional oil recovery. However, it was observed that changing the concentration of the injected brine improved oil recovery in a process termed low-salinity flooding (Lager et al. 2008). Low-salinity water flooding (LSF) is an evolving technique of EOR, where the salinity of injected waters is controlled to improve oil recovery (Robertson 2007; Nasralla and Nasr-El-Din 2011; Bedrikovetsky and Zeinijahrami 2015; Kumar et al. 2016). It is an enhanced oil recovery method that uses water with low concentration of the dissolved salts as a flooding medium (Sheng 2014). The sources of low-salinity water are usually lakes, rivers or aquifers that associated with meteoric water (Schlumberger 2017). Low salinity of water flooding has widely practiced as an EOR technique and is relatively cheaper and environmentally friendly among other conventional recovery techniques (Suman et al. 2014; Sheng 2014).

In recent years, many researchers (Mcguire et al. 2005; Vledder et al. 2010; Aladasani et al. 2012; Fjelde et al. 2012; Al-Attar et al. 2013; Alameri et al. 2014; Hamouda et al. 2014; Bartels et al. 2016) have conducted laboratory core floods, and several companies have carried field tests to ascertain the feasibility of low-salinity flooding for improved oil recovery. Several displacement mechanisms of low-salinity recovery process have been proposed by researchers. These proposed displacement mechanisms for low-salinity flooding are wettability alteration, $\mathrm{pH}$ increase, fines migration, clay swelling, multicomponent ion exchange (MIE), salting-in, cation exchange (Austad et al. 2010). However, there is no agreement on the dominant mechanism(s) of low-salinity displacement (Cissokho et al. 2010; Sorbie and Collins 2010; Austad et al. 2010; Kumar et al. 2010; Alotaibi et al. 2011; Nasralla et al. 2011, 2013; Nasralla and Nasr-el-din 2012; Hamouda et al. 2014; Alquraishi et al. 2015; Shabib-Asl et al. 2015; Sohrabi et al. 2015; Mahani et al. 2015; Qiao et al. 2016; Fredriksen et al. 2016, 2017) given that there are evidences that improved oil recovery by low-salinity flooding (LSF) was achieved through a combination of the mechanisms working simultaneously in tandem.

Consequently, a consensus reached by researcher and their studies is that fluid-rock and fluid-fluid interactions are the bedrock of all EOR displacement mechanisms, and the alteration of the equilibrium state is what effects additional oil recovery. A variety of literature has shown the prevalence of chemical or physical attributes of the brines and crude oil on the effects on LSF for EOR. A description of the conditions for low-salinity effect in sandstones can be seen in the combined works of Tang and Marrow (1999) and Lager et al. (2008). The presence of clays in the porous medium, which is one of the conditions for LSF, has since been contested by Al-Saedi et al. (2019a) that, despite improving oil recovery during LSF, it does not necessarily mean that it must be present for low-salinity effects to occur. Other conditions include presence of polar components of oil and the chemical make-up of the formation and low-salinity water (Rezaeidoust et al. 2009). Lowering the concentrations of the low-salinity water (LSW) and adjusting its salt composition has a combined effect of increasing the potential of the flooding process in what is referred to as "smart water" flooding (Ding and Rahman 2017). For sandstones reservoirs, LSW with less multivalent ions $\left(\mathrm{Mg}^{2+}\right.$, $\left.\mathrm{Ca}^{2+}, \mathrm{SO}_{4}{ }^{2-}\right)$ in the brine is more beneficial with a salinity of between 1000 and 4000 ppm (Rezaeidoust et al. 2009), but some laboratory tests showed an additional recovery at even higher concentrations of up to $6000 \mathrm{ppm}$ (Shiran and Skauge 2012). One aspect of the LSF technique borders on the wettability alteration of the reservoir rock, both carbonates and sandstones, which involves several interacting forces. The $\mathrm{pH}$ of the LSW, its composition, and salinity affect the surface charge of the rock and the overall chemistry of the fluid interface. It suffices to say that these combined effects influence the wettability of the reservoir rocks.

Wettability alteration by modification of clays by LSF was proved by Berg et al. (2010) and inferred that the most relevant mechanisms of displacement for LSF include interfacial tension (IFT) reduction which leads to the emulsification of water and oil, fines migration and pore plugging from clays swelling through water imbibition. The reservoir rock wettability can be altered by the chemical interaction of the divalent ions which alters the surface chemistry of the rock which leads to desorption of the oil by changing the wettability (Yousef et al. 2010). Moustafa and Shedid (2018) conducted an experiment on sandstone cores and investigated the influence of magnesium $\left(\mathrm{MgSO}_{4}\right)$ and potassium $\left(\mathrm{K}_{2} \mathrm{SO}_{4}\right)$ sulphates on oil recovery by water injection in sandstones. They alluded that increasing the concentration of the sulphate salts in their "smart water" formulation yielded higher recovery. They varied the sodium chloride $(\mathrm{NaCl})$ concentration 
with the sulphates and attributed the improved recovery to changing the wettability of the core sample to a more water wet state, the $\mathrm{pH}$ increase and the decrease in $\mathrm{NaCl}$ salts. It is common knowledge that $\mathrm{NaCl}$ is considered nonactive in terms of LSF (Darvish Sarvestani et al. 2019). This has been shown to be as a result of the monovalent sodium ion $\left(\mathrm{Na}^{+}\right)$, in that, it does not have any wettability altering properties in the presence of other divalent cations like $\mathrm{Mg}^{2+}$. But Darvish Sarvestani et al. (2019) stated that $\mathrm{KCl}$, a monovalent salt, can change the rock wettability to more water wet and improved oil recovery can be realised. Suman et al. (2014), however, used $\mathrm{NaCl}$ brines for core flooding experiments and realised increased recovery of oil by reducing the concentrations. This is evident that even the monovalent ions do have an influence in effecting the improved recovery through a combination of displacement mechanisms.

Clearly, the anionic component of the salt can also have an influence on the wettability alteration and other mechanism of LSF. Cationic effects are mostly considered when dealing with LSF mechanism like wettability alteration in sandstones. To the author's knowledge, no exclusive investigations have been carried out to evaluate the roles of anionic components, chlorides and sulphates, of the brines and formation water interaction during LSF in sandstones. This study focuses on the combined effects of the injected lowsalinity brines in a smart water-low-salinity approach on improved recovery. Laboratory experiments using low and high-salinity brines, of equal concentration, were carried out to evaluate the influence of chloride- and sulphate-based brines on improved oil recovery during water flooding. Other mechanisms of displacement as a result of this smart water formulation will also be evaluated in this study.

\section{Experimental methodology}

To investigate the influence of chloride- and sulphate-based brines, numerous core flooding experimentations were carried out. A series of preliminary tests, like the core sample characterisation, was first carried out to evaluate the petrophysical properties of native core samples obtained from Southern Kuwait.

\section{Mineralogical determination}

Using energy-dispersive X-Ray spectroscopy (EDX) and $\mathrm{X}$-ray diffraction (XRD) analysis, the core samples were found to be made up of majority quartz $\left(\mathrm{SiO}_{2}\right)$. Interestingly, there were trace amounts of kaolinite clay in the core sample and shown in Table 1. The analyses are shown in Figs. 1 and 2 and Table 2.
Table 1 Composition of the core samples from EDX analysis

\begin{tabular}{lllc}
\hline S. no & Compound & Chemical formula & Content (\%) \\
\hline 1 & Quartz & $\mathrm{SiO}_{2}$ & 87.2 \\
2 & Pyrite & $\mathrm{FeS}_{2}$ & 4.2 \\
3 & Halite & $\mathrm{NaCl}$ & 1.8 \\
4 & Sylvite & $\mathrm{KCl}$ & 0.4 \\
5 & Aluminium silicate & $\mathrm{Al}_{0.5} \mathrm{Si}_{0.75} \mathrm{O}_{2.25}$ & 1.2 \\
6 & Kaolinite & $\mathrm{Al}_{2} \mathrm{SiO}_{5}(\mathrm{OH})_{4}$ & 5.2 \\
\hline
\end{tabular}

\section{Core sample preparation}

The dimensions of the four (4) native core samples utilised in the experimentation are shown in Table 3.

The first step in a core sample preparation for core flooding experimentation is core cleaning. This is an essential step which removes any residual "impurity" residing within the pore spaces of the core sample which will most likely contaminate the test fluids and invariably erroneous results. These impurities can be residual crude oil from the site of acquisition or salt precipitates from the formation water. This involved using Soxhlet Extraction which utilises toluene (99.8\% purity) to remove any organic material within the pore matrix of the core samples followed by cleaning with methanol ( $99.5 \%$ purity) all obtained from Sigma-Aldrich UK. Oven drying, for $24 \mathrm{~h}$, of the core samples at $100{ }^{\circ} \mathrm{C}$ was performed to obtain the dry weight for porosity measurement.

The core samples were immersed in a vacuum chamber, shown in Fig. 3 and saturated with distilled water for porosity measurements. This was left in the chamber for $48 \mathrm{~h}$ under vacuum to ensure proper saturation. Weights of each core sample were measured and used to evaluate the pore volume of each core sample using the relation:

Pore volume $\left(\mathrm{cm}^{3}\right)=$

Wet weight of sample $(\mathrm{g})$ - Dry weight of sample $(\mathrm{g})$

$$
\text { Density of distilled water }\left(\frac{\mathrm{g}}{\mathrm{cm}^{3}}\right)
$$

The core samples were then dried at $120{ }^{\circ} \mathrm{C}$ in a convection oven, after repeated experiments with a standard deviation $(\sigma)$ of $0.74 .0 .67,0.14,0.88 \mathrm{~cm}^{3}$ for each of the four core samples used.

\section{Brine preparation}

Formation brine with different salt types was prepared using the formation water composition of Southern Kuwait as template. The different brine types prepared for this study are shown in Table 4, and the concentration and

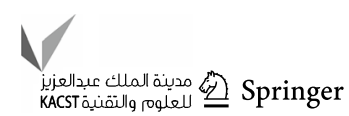




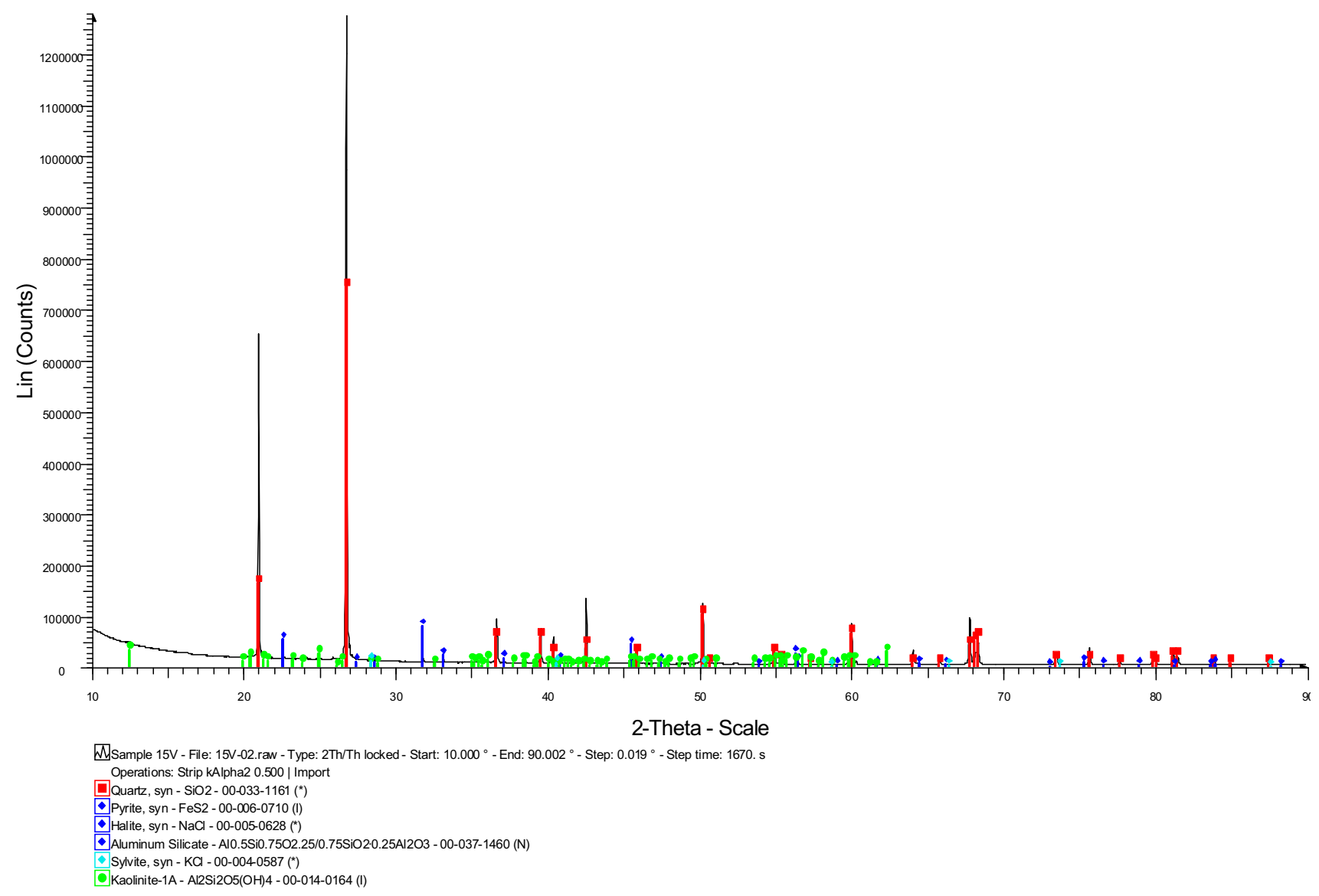

Fig. 1 XRD results showing peaks of identified compounds

ionic distribution are shown in Table 5. They are designed in such a way that the composition accentuates the aim set out to evaluate the effects of sulphate- and chloridebased salts, in this study. High-salinity chloride- and sulphate-based salts of about 70,000 ppm concentration and their low-salinity counterparts of $5000 \mathrm{ppm}$ were prepared and used for the experimentation. Equal amounts of the classes of salts were measured using high accuracy weighing balance to prepare the desired concentration of both high- and low-salinity brines. These were added to distilled water in a round-bottom flask and stirred using a magnetic stirrer at low rate for uniform dissolution of the salts for $2 \mathrm{~h}$. After all the salt has dissolved in the brine; the contents were stored in glass containers with a sealing cover after being labelled accordingly. The $\mathrm{pH}$, densities, and viscosities were measured and recorded. The brines were designed in such a way that the level of divalent cation was minimised so as to lessen the effects it has on the displacement mechanism for low-salinity water flooding.

\section{Core flooding process}

After the two previous steps, core sample cleaning and brine preparations, the core sample was externally saturated with the desired brine prepared using the same vacuum set-up used for the vacuum saturation in Fig. 3. This was also left for $24 \mathrm{~h}$ to ensure full saturation and then loaded into the core holder of the core flooding process. The schematic of the set-up is shown in Fig. 4. The set-up works on the principles of Darcy Law and is governed by Darcy Equation:

$K=\frac{14700 v \mu L}{\Delta p A t}$

$K$ is permeability $(\mathrm{mD}), V$ is flow volume $(\mathrm{mL}), L$ is length of flow (cm), $\mu$ is viscosity (centipoises), $\Delta p$ is differential pressure (psig), $t$ is time (s), and $A$ is cross-sectional area of flow $\left(\mathrm{cm}^{2}\right)$.

Using $0.5,0.75,1.0 \mathrm{ml} / \mathrm{min}$ injection rates, the brine that was used in the vacuum saturation was then injected into the 

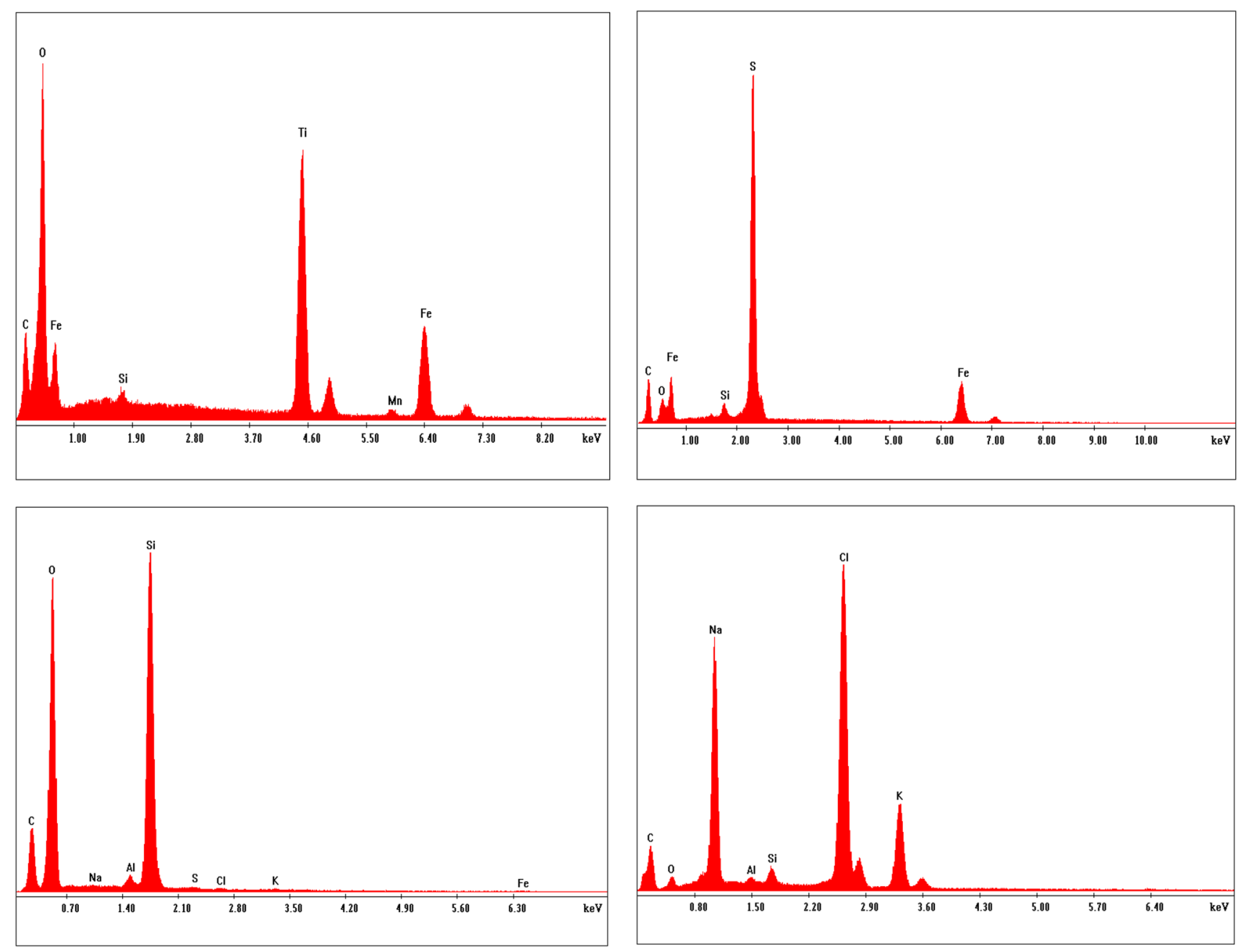

Fig. 2 EDX results at different angles of exposure

Table 2 EDX identified elements of the core samples

\begin{tabular}{lll}
\hline S. no & Element & Name \\
\hline 1 & $\mathrm{C}$ & Carbon \\
2 & $\mathrm{O}$ & Oxygen \\
3 & $\mathrm{Fe}$ & Iron \\
4 & $\mathrm{Si}$ & Silica \\
5 & $\mathrm{Ti}$ & Titanium \\
6 & $\mathrm{Mg}$ & Magnesium \\
7 & $\mathrm{Al}$ & Aluminium \\
8 & $\mathrm{~S}$ & Sulphur \\
9 & $\mathrm{Cl}$ & Chlorine \\
10 & $\mathrm{~K}$ & Potassium \\
11 & $\mathrm{Na}$ & Sodium \\
12 & $\mathrm{Mn}$ & Manganese \\
\hline & &
\end{tabular}

externally saturated core sample to ensure full saturation. With each flow rate, the injection was stopped only when the differential pressure $(\mathrm{dP})$ becomes constant.
When this steady dP state was reached, with all the increments in the flow rate ranges, crude oil was then injected into the brine saturated core sample at $0.2 \mathrm{ml} / \mathrm{min}$ in a long flow procedure (about $15 \mathrm{PV}$ of oil) and initial water saturation (Swi) was established along with the oil initially in place (Soi). The crude oil was obtained from the Burgan Field of Kuwait with an API gravity of $30^{\circ}$ and viscosity of $5.2 \mathrm{cp}$ at $23{ }^{\circ} \mathrm{C}$. After a steady dP was achieved in this case, the injection pumps were stopped, and the set-up was left for $48 \mathrm{~h}$ under an overburden pressure of 2500 psi (simulating reservoir depths of $\sim 5000 \mathrm{ft}$ ) and pore pressure of $1500 \mathrm{psig}$. The temperature of the core holder is maintained at $80^{\circ} \mathrm{C}$. This was done to age the core sample in order to restore its original wettability which was altered through the cleaning processes using the organic solvents.

After the ageing time, the displacement process was carried out with different brine concentrations according to the classification made in Table 5. The temperature was set to $50{ }^{\circ} \mathrm{C}$, and the injection commenced at constant rate $0.5 \mathrm{ml} /$ 
Table 3 Dimension and petrophysical properties of core samples

\begin{tabular}{llllllll}
\hline S. no & Core sample & Diameter $(\mathrm{cm})$ & Length $(\mathrm{cm})$ & PV & $\begin{array}{l}\text { Absolute brine } \\
\text { permeability } \\
(\mathrm{md})\end{array}$ & Porosity $(\%)$ & Swi (\%) \\
\hline 1 & 1A & 3.81 & 4.91 & 13.9 & 131.3 & 24.9 & 20.9 \\
2 & 1B & 3.81 & 5.01 & 13.3 & 112.5 & 23.3 & 24.4 \\
3 & 1C & 3.81 & 4.81 & 11.3 & 189.7 & 20.6 & 20.8 \\
4 & 1D & 3.82 & 4.86 & 11.2 & 57.2 & 20.2 & 17.9 \\
\hline
\end{tabular}

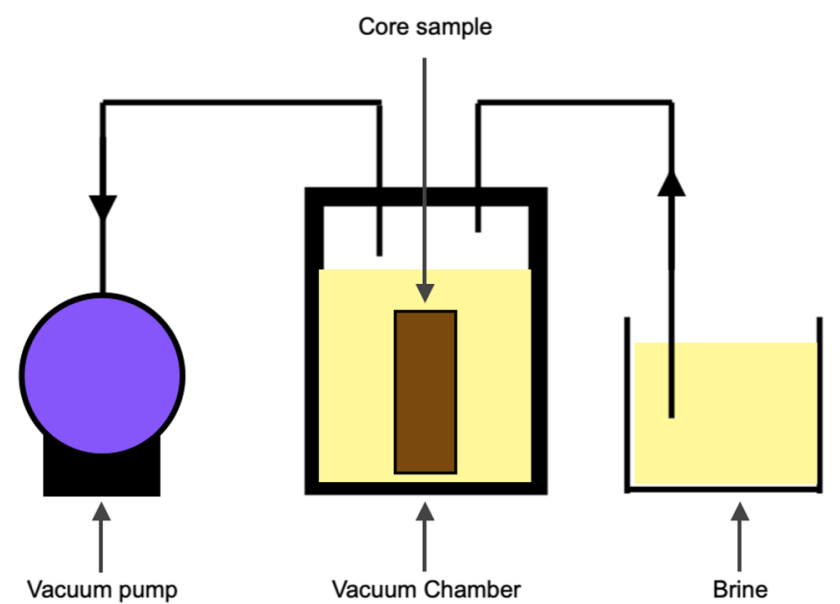

Fig. 3 Vacuum saturation set-up

Table 4 Salts used in the preparation of the brines

\begin{tabular}{lll}
\hline & Sulphates & Chlorides \\
\hline 1 & $\mathrm{Na}_{2} \mathrm{SO}_{4}$ & $\mathrm{NaCl}$ \\
2 & $\mathrm{CaSO}_{4}$ & $\mathrm{CaCl}_{2}$ \\
3 & $\mathrm{~K}_{2} \mathrm{SO}_{4}$ & $\mathrm{KCl}$ \\
\hline
\end{tabular}

Table 5 Composition of brine formulations used in the experiments

\begin{tabular}{lllll}
\hline Components & $\begin{array}{l}\text { Hi Sal sul- } \\
\text { phates }\end{array}$ & $\begin{array}{l}\text { Hi Sal chlo- } \\
\text { rides }\end{array}$ & $\begin{array}{l}\text { Low Sal } \\
\text { sulphates }\end{array}$ & $\begin{array}{l}\text { Low Sal } \\
\text { chlorides }\end{array}$ \\
\hline $\begin{array}{l}\text { Cations } \\
\mathrm{Na}+\end{array}$ & 9660 & 19,700 & 480 & 980 \\
$\mathrm{Ca}^{2+}$ & 4400 & 7960 & 440 & 800 \\
$\mathrm{~K}^{+}$ & 1450 & 2600 & 290 & 520 \\
Anions & & & & \\
$\mathrm{SO}_{4}{ }^{2-}$ & 54,490 & & 3790 & \\
$\mathrm{Cl}^{-}$ & & 39,740 & & 2700 \\
$\mathrm{TDS}^{\text {Ionic conc. }}$ & 1.58 & $\mathbf{7 0 , 0 0 0}$ & $\mathbf{5 0 0 0}$ & $\mathbf{5 0 0 0}$ \\
$\quad(\mathrm{M})$ & & 1.33 & 0.11 & 0.10 \\
$\mathrm{Brine} \mathrm{pH}$ & 6.6 & 6.8 & & \\
$\quad\left(25{ }^{\circ} \mathrm{C}\right)$ & & & 7.8 & 7.9 \\
\hline
\end{tabular}

Bold showcases the concentrations of the brines used which is the foundation of the research min using an ISCO model 500D injection pumps while maintaining the pore pressure within 1500 psig with a dometype back pressure regulator. The reference pressure on the back-pressure regulator was supplied by compressed nitrogen gas which is best suited for the fluctuation and smoother flow as opposed to hydraulic oil. Overburden pressure of 2500 psig was maintained using a hydraulic pump model S-216-JN-150 over the core sample in a Viton sleeve housed in a Hassler-type core holder. Using an integral part of core flooding system, supplied by CoreLab Oklahoma, the SmartFlood software and computer data acquisition and control system displayed and recorded all measured values in realtime and for post-processing. Effluents from the downstream of the core holder were collected in measuring cylinders. Each experimental run came to a stop when the effluents contained negligible or no oil at all, meaning high water cut. The $\mathrm{pH}$ of the effluent water was thus measured using $\mathrm{pH}$ meter (obtained from Eutech Instrument) for further analyses and inferences. This was carried out for all the test brines investigated for the experiments in this study.

\section{IFT measurement}

To reiterate the possible effects of the brines investigated, the IFTs between the brines and oil were measured for the investigated brine concentrations and species. A CoreLab surface energy experimental apparatus was used to measure the IFT in this study. Rising bubble method was used to generate the bubble and a Rame-Hart high-speed optical system with a digital image processing software which was used to evaluate the parameter based on bubble size and density of the fluids investigated. The schematic is shown in Fig. 5. Here, the external phased is the brine which was charged into the IFT cell and pressurised to 1500 psig at a temperature of $50{ }^{\circ} \mathrm{C}$. After the pressure was stable, the drop phase (oil) was injected into the external phase in form of a bubble and the measurements were taken as shown in Fig. 6. The same procedure was followed for all the brine concentrations, several times for repeatability. The cell and lines were cleaned before starting a new experiment by flushing the system with acetone, methanol, distilled water for the removal of organic, inorganic compounds, and residues from the system, respectively. 


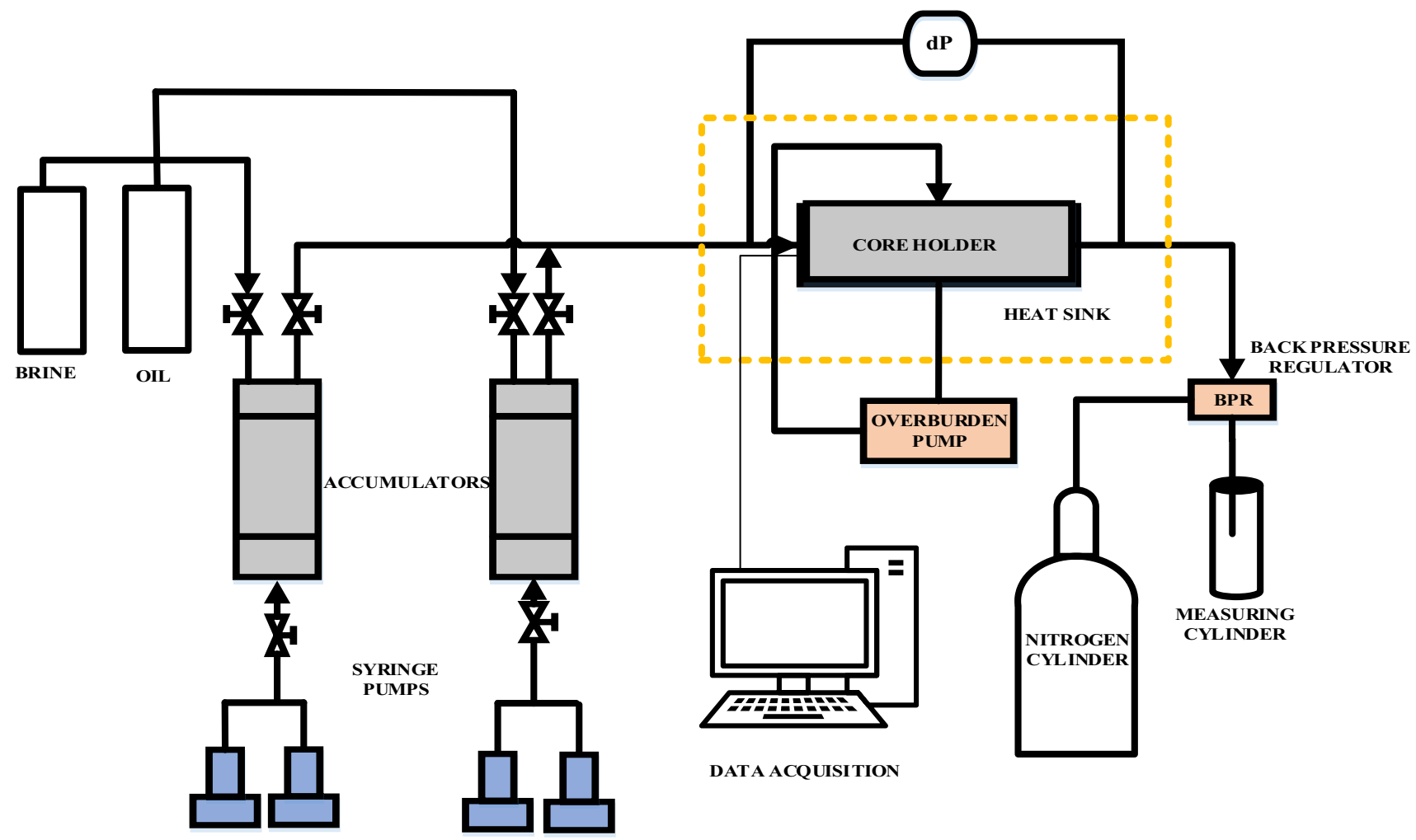

Fig. 4 Core flooding set-up schematics

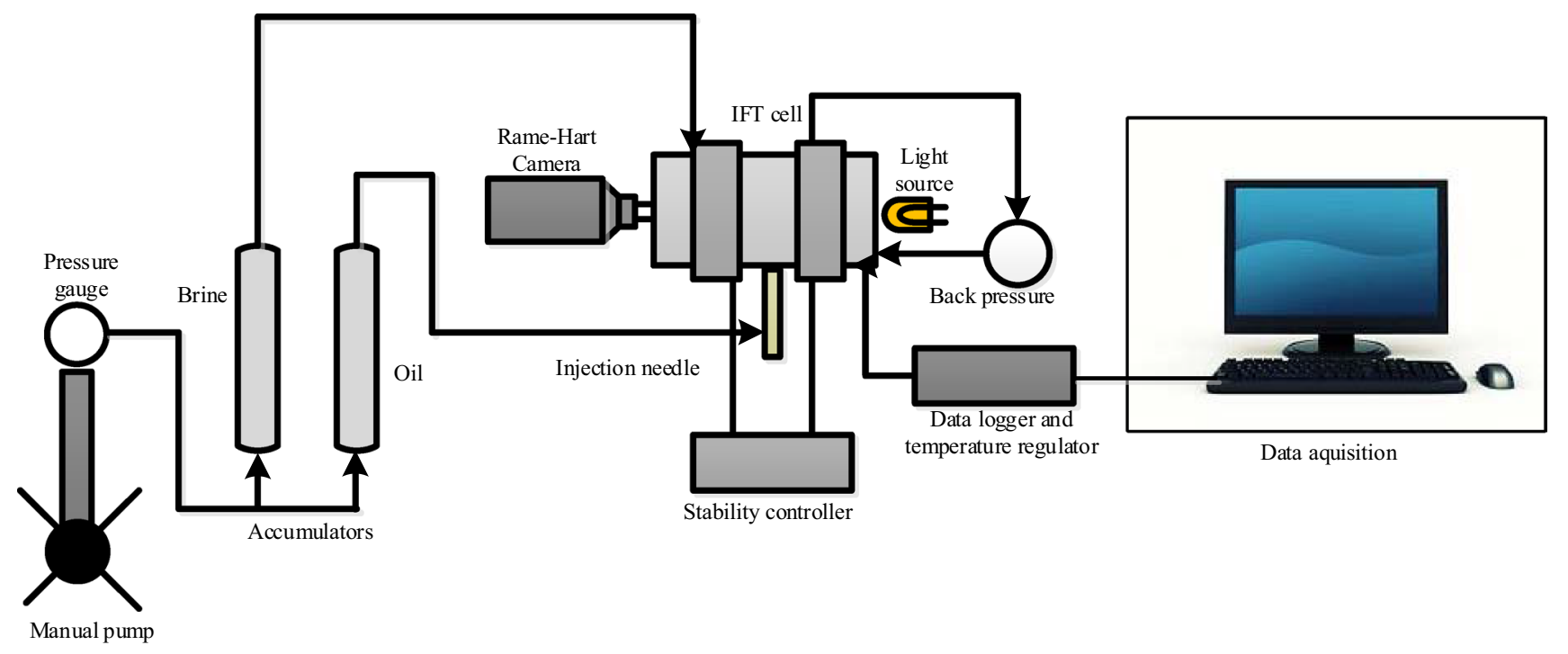

Fig. 5 IFT measurement set-up schematics

This method of IFT measurement banks on the density difference between the external phase and the drop phase, in that the oil tends to rise within the external phase. The IFT is evaluated using the principle of Young-Laplace equation:
$\gamma=\frac{\Delta \rho g d_{\mathrm{e}}^{2}}{H}$

where 

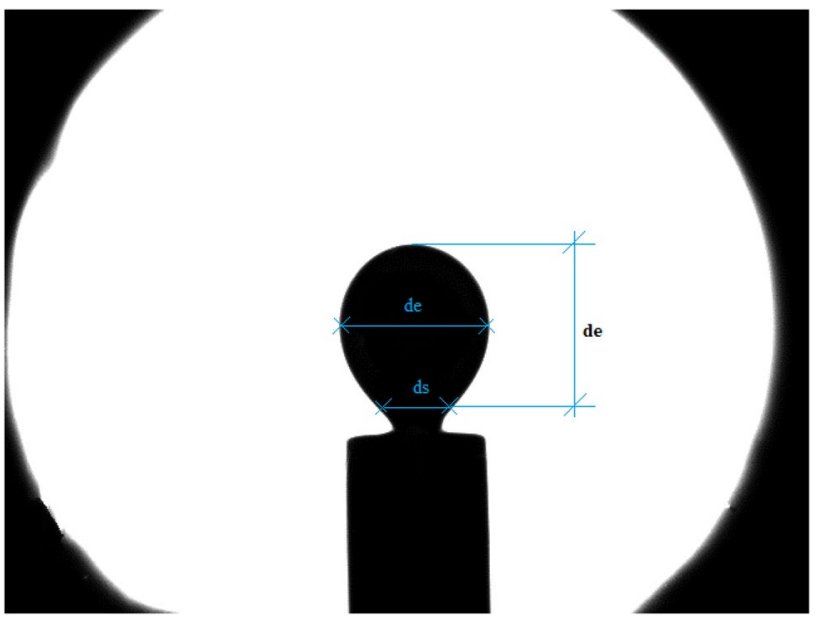

Fig. 6 Oil droplet for IFT measurement showing dimension

$\frac{1}{H}=f\left(\frac{d_{\mathrm{s}}}{d_{\mathrm{e}}}\right)$

$\Delta \rho$ is the density difference between the two fluids, $\gamma$ is the interfacial tension, $g$ is the acceleration due to gravity, $d_{\mathrm{e}}$ is equatorial diameter of the drop, $d_{\mathrm{s}}$ is the diameter of the bubble at de from the apex, $H$ is the bond number which is a function of the ratio of $d_{\mathrm{s}} / d_{\mathrm{e}}$. A depiction of these parameters shown in an actual IFT image captured in this work is shown in Fig. 6.

\section{Results and discussion}

\section{Core flooding}

The oil recovery processes in each simulated displacement scenario employing different salt types and concentration were investigated using laboratory core flooding technique as described in "Core flooding process" section. This facilitated the determination of the displacement efficiency of each salt type to evaluate the effect of tinkering with the salt species composition and concentration. Results of the core flooding experiments are as follows. Note that, for the purpose of comparison, distilled water runs were carried out to provide a benchmark for the subsequent tests. Each classification of the brines was compared to distilled and presented.

\section{High-salinity displacement tests and effects of salt presence in brines}

The 70,000 ppm sulphate and chloride brines were used to saturate the core sample and displace the initial oil (Soi) using the aforementioned conditions to evaluate the displacement efficiency. Prior to the displacement test, distilled

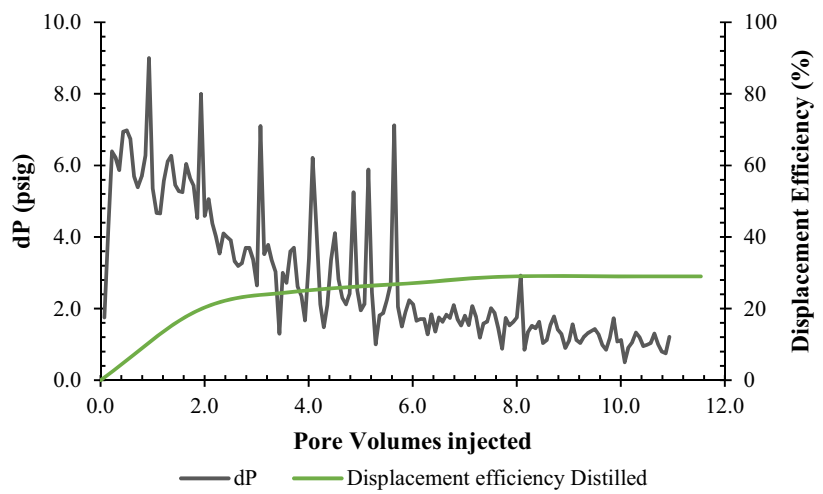

Fig. 7 Displacement efficiency and $\mathrm{dP}$ trend of oil displacement using distilled water

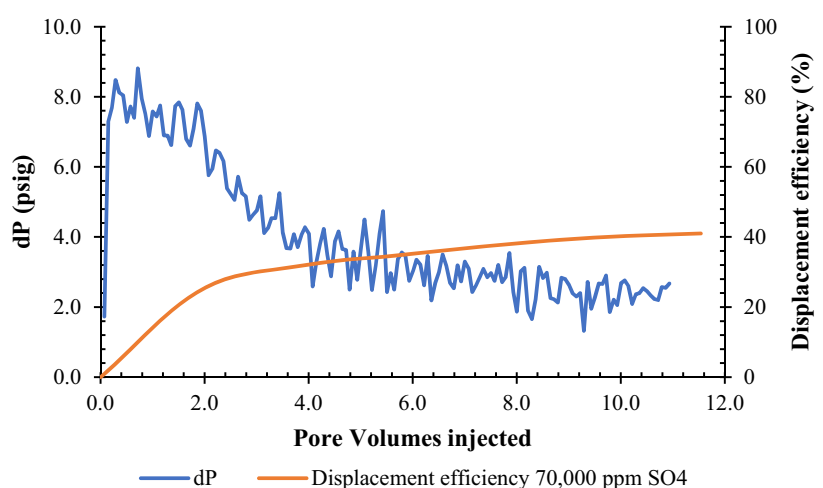

Fig. 8 Displacement efficiency of high-salinity sulphate brine

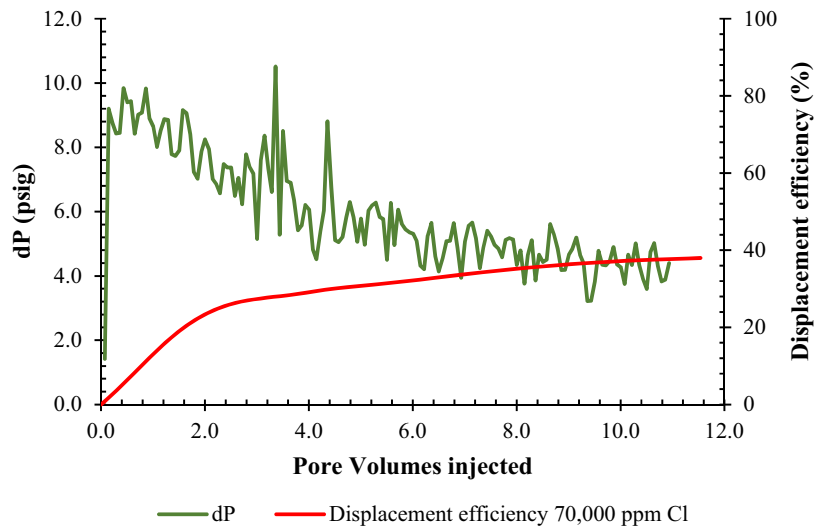

Fig. 9 Displacement efficiency of high-salinity chloride-based brine at test conditions

water was used as the displacing fluid after saturating the rock with high-salinity brine and oil, and Swi and Soi were established. This, as already stated, serves as a benchmark for other displacement tests. The result is shown in Fig. 7. The displacement efficiency was characteristically poor 
owing to poor sweep efficiency of distilled water as a displacement fluid.

Subsequently, Figs. 8 and 9 show the results from oil displacement by high-salinity sulphate- and chloride-based brines, respectively. They appeared to have better displacement/recovery efficiencies compared to distilled water experiment. This is evidence that the presence of ions in the displacement fluid tends to upset the equilibrium established by the formation fluids within the pore matrix of the porous medium and as such improve oil recovery through different mechanisms.

The presence of salts can be seen to improve the oil displacement (compared to distilled water), to a certain degree, when the displacement process was carried out using $70,000 \mathrm{ppm}$ brines. This was to simulate conventional waterflooding technique where the formation water is reinjected into the reservoir to improve oil recovery by re-energising the reservoir and increase the macroscopic sweep efficiency. Interestingly, better displacement of the oil by high-salinity brines over the distilled water was realised. There was obvious substantial bypassing of the oil in the distilled water scenario as seen in the dP fluctuations in Fig. 7 and the early breakthrough of distilled water during the displacement. Rezaeidoust et al. (2009) reported that multicomponent ion exchange only takes place in low-salinity conditions in sandstone reservoirs. Thus, they stated that when there is a different relative concentration of the injected brine of the active ions compared to the formation water, there could be an exchange of ions which could alter the wettability of the rock sample and possible improved oil recovery. This, however, was not the case as there was no dilution of the injected brines. Given that the anionic components from the carboxylates of the crude oil, through cationic bridging, adsorb onto the positively charged rock surface in sandstones reservoirs, the influx of the high-salinity displacing brine, with the same concentration as the connate water, does little to upset the equilibrium between the rock-fluid interface.

Additionally, the effluent $\mathrm{pH}$ remained unchanged (see Fig. 15) after the distilled water and high-salinity brines $(70,000 \mathrm{ppm})$ displacement tests, further indicating that there was no apparent interaction between the intermediate-wet rock and the displacing fluids. In all the core samples used, this was the trend observed. Furthermore, albeit the same concentration of 70,000 ppm of both $\mathrm{Cl}$ and $\mathrm{SO}_{4}$ brines, better recovery was observed with $\mathrm{SO}_{4}$ brines compared to the $\mathrm{Cl}$ flooding scenario as can be seen in Fig. 10 . This can be attributed to the $\mathrm{Ca}^{2+}$ concentration in Swi in both cases (see Table 5). Because of the nature of $\mathrm{SO}_{4}$ ion, lower amount of $\mathrm{Ca}^{2+}$ is needed to balance the aqueous solution unlike the $\mathrm{Cl}$ solution which requires more. And it has been established that the higher the concentration of $\mathrm{Ca}^{2+}$ in the initial saturation, the more oil-wet the core plugs will be (Yang et al. 2016). Thus, the increased concentration of

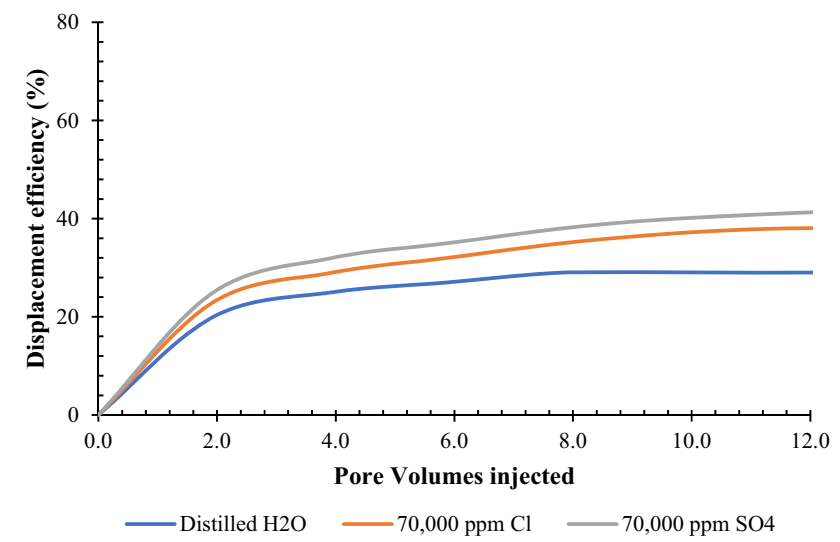

Fig. 10 Comparison of displacement efficiencies of high-salinity brines

the $\mathrm{Ca}^{2+}$ ion in the thin water film between the rock and the oil infers more positive interface which decreases the electrostatic repulsion between the rock surface and the anionic components of the crude oil. As such, the $\mathrm{Ca}^{2+}$ bridges become stronger, than the van der Waals forces, in the $\mathrm{Cl}$ flooding scenario and invariably less oil desorption which leads to poor recovery compared to the $\mathrm{SO}_{4}$ scenario. So, the higher the $\mathrm{Ca}^{2+}$ concentration in the formation water, the more the adhesion of the carboxylate component of the crude oil to the rock surface thereby rendering it more hydrophobic. This is one of the reasons why the recovery in high-salinity $\mathrm{Cl}$ brine displacement was lower than $\mathrm{SO}_{4}$ at the same concentration. Additionally, this confirmed the statement by Rezaeidoust et al. (2009) that high-salinity brines should not show low-salinity effects in sandstones. Figure 8 shows the displacement efficiency and dP fluctuations during high-salinity $\mathrm{SO}_{4}$ run. There is an improvement in the breakthrough time of the flooding compared to the distilled water. And the flow behaviour shows less $\mathrm{dP}$ fluctuations meaning there is to some degree a homogeneous movement in the binary fluids. Admittedly, the interplay between the fluids in the Cl-based displacement shows similar trends as the distilled water run. In Fig. 9, the dP fluctuations are intense for the $\mathrm{Cl}$ run indicating there was no synergy between the transporting fluids, invariably showing that lower displacement efficiency is expected from such runs. More discussion is in Sect. 3.3.

\section{Low-salinity effects of $\mathrm{SO}_{4}$ and $\mathrm{Cl}$ brines}

Consistently, when the displacement brines concentrations were switched to $5000 \mathrm{ppm}$, with initial oil water saturation (Swi) at 70,000 ppm (to fulfil one of the conditions of low-salinity effect-presence of connate water according to Rezaeidoust et al. (2009), a different and interesting trend was observed. Figure 11 shows a comparison of

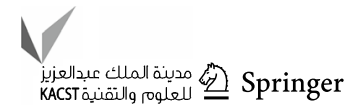




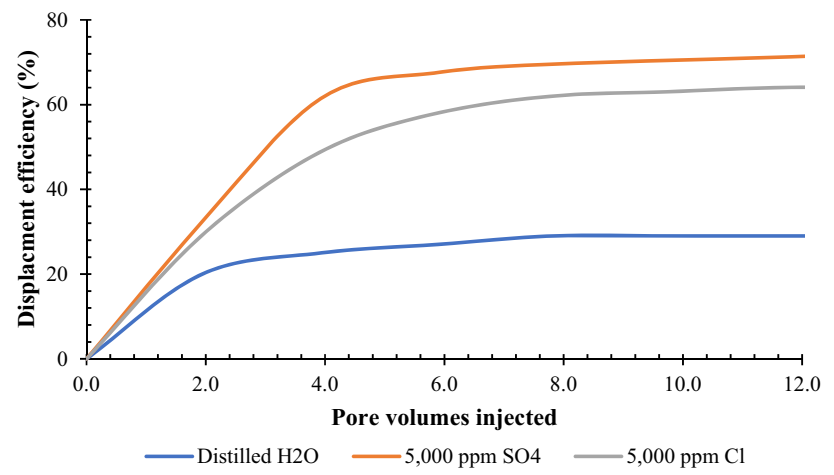

Fig. 11 Comparison of displacement efficiencies of low-salinity brine formulations

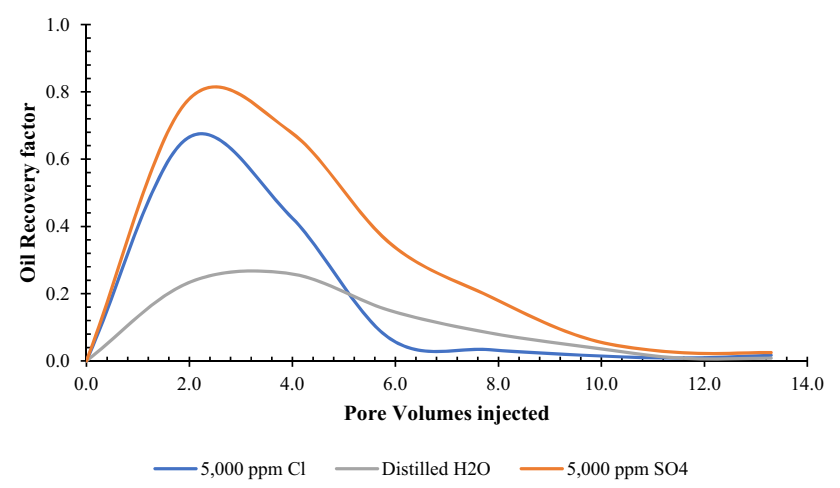

Fig. 12 Instantaneous oil recovery for low-salinity scenario

displacement efficiencies between the low-salinity brines and distilled water. An instantaneous recovery of low-salinity brines is shown in Fig. 12 which indicates the macroscopic sweep of each brine flooding scenario. The largest initial recovery was realised in the $5000 \mathrm{ppm} \mathrm{SO}_{4}$ brine, and production was sustained longer than the other flooding scenarios. The lowest instantaneous recovery was realised after 10 pore volumes of the brine was injected for the $\mathrm{SO}_{4}$ scenario while production peaked at about 3 pore volumes. Worst case scenario was the distilled water where production peaked at about 4 pore volumes with about 0.25 recovery efficiency indicating a poor sweep efficiency. Intermediate recovery was seen in the $\mathrm{Cl}$ case with instantaneous production peaking at 2 pore volumes, and there was no production sustenance as seen in the rapid drop in production after 6 pore volumes of $5000 \mathrm{ppm} \mathrm{Cl}$ brine were injected. The intersection between the distilled water and Cl-based scenario is indicative of the fact that at that point, the recovery efficiencies of both scenarios are the same. There is a significant improvement in the displacement efficiencies of each injection scenario compared to the high-salinity counterpart, also shown in Fig. 13. Careful measures were taken to satisfy the conditions of low-salinity flooding in sandstone reservoirs.

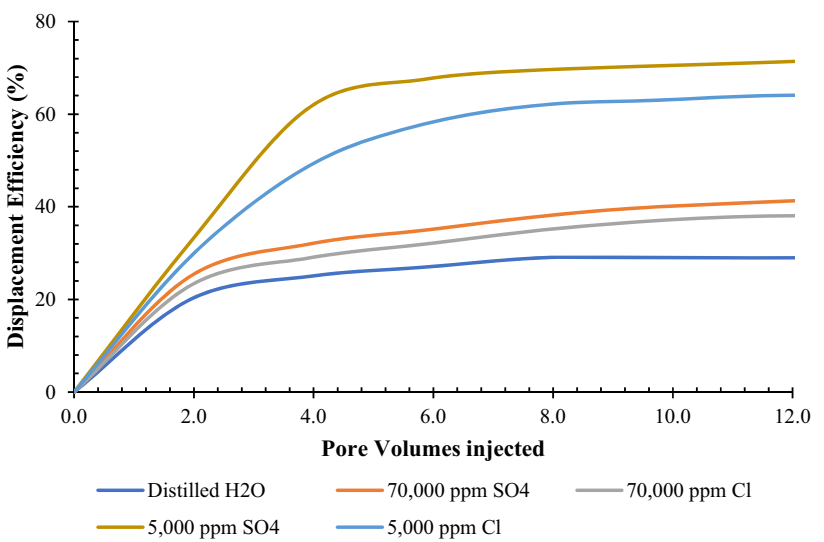

Fig. 13 Evaluation of displacement efficiencies of all the brines used in the experiment

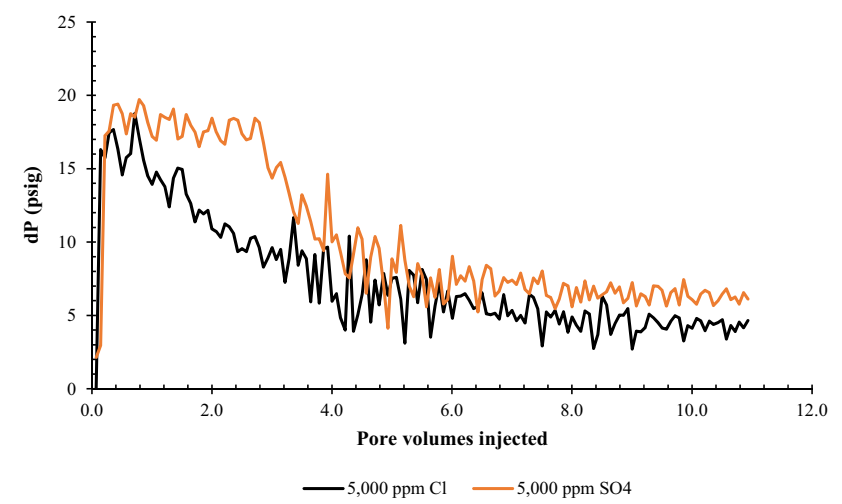

Fig. $14 \mathrm{dP}$ versus pore volumes injected for low $\mathrm{Cl}$ and $\mathrm{SO}_{4}$

As already established, lowering the concentration has the potential to improve oil recovery.

Several mechanisms of displacement of oil using LSF can be attributed to this significant oil recovery with low-salinity effects while others can be ruled out. Figure 14 shows there was no increase in $\mathrm{dP}$ as the low-salinity brine (both $\mathrm{Cl}$ and $\mathrm{SO}_{4}$ ) displaced the oil in the porous medium and there were no visible solids upon physical inspection of the effluents. Therefore, fines migration as a displacement mechanism can be disregarded as it is characterised by an increase in $\mathrm{dP}$ (indicating lower permeability of the fluids to the porous media) as reported by Tang and Morrow (1999) after breakthrough. The increase in the resistance to flow through pore channels indicates that clays and other fines may have been dislodged/relocated and have plugged narrower pore channels within the porous matrix as a result of flooding. This phenomenon was not observed in all the experimental runs carried out in this work.

In the $5000 \mathrm{ppm} \mathrm{SO}_{4}$ brine scenario, as the $70,000 \mathrm{ppm}$ runs, the recovery efficiencies were higher than the $\mathrm{Cl}$ and distilled water runs as seen in Figs. 10 and 11 clearly, despite 
the higher ionic strengths of $\mathrm{SO}_{4}$ in all both scenarios (Table 5). When the ionic strength was lowered, it facilitated the improved recovery by altering the wettability of the core rock in both sandstones and carbonates (Rezaei Gomari and Joseph 2017), which is contrary to what was observed here. Furthermore, the active cationic count of the low-salinity $\mathrm{SO}_{4}$ was lower than the low-salinity $\mathrm{Cl}$. This comes down to the anionic components of the brines which play roles in the improved oil recovery. A proposed mechanism for the role of $\mathrm{SO}_{4}$ in LSF is presented in Eqs. (5) to (7). A study by Rezaeidoust et al. (2009) postulated that $\mathrm{SO}_{4}$ can act as a catalyst in a way and a possible school of thought is that it replaces the carboxyl ion in the cation or ligand bridge with the rock surface at sites where protonation has not occurred.

$>\mathrm{SiOCaCOO} \leftrightarrow>\mathrm{SiO}^{-}+\mathrm{Ca}^{2+}+\mathrm{COO}^{-}$

$>\mathrm{SiO}^{-}+\mathrm{Ca}^{2+}+\mathrm{SO}_{4}^{2-} \leftrightarrow \mathrm{SiOCaSO}_{4}^{-}$

$>\mathrm{SiOCaSO}^{-}+\mathrm{H}^{+} \leftrightarrow \mathrm{SiOCaHSO}_{4}$

$>\mathrm{SiO}^{-}+\mathrm{Ca}^{2+}+\mathrm{Cl}^{-} \leftrightarrow \mathrm{SiOCaCl}$

Repulsion of the carboxylate group of the crude oil by the now negative surface of the rock will promote the desorption of the organic material from rock surface by overcoming the electrostatic van der Waals forces binding the oil to the rock surface. The $\mathrm{pH}$ at the rock surface/brine interface is lowered i.e. more acidic $(\mathrm{pH}<7)$ where the $\mathrm{H}^{+}$affinity towards the mineral surface increases as depicted in the works of Chen et al. (2018). This further stimulates the multicomponent ion exchange (MIE) where the surface $\mathrm{Ca}^{2+}$ is replaced by the $\mathrm{H}^{+}$. The desorption of $\mathrm{Ca}^{2+}$ from the surface severs the cation bridging and a better microscopic sweep is realised; hence, more oil is recovered.

In Fig. 13, the $5000 \mathrm{ppm} \mathrm{SO}_{4}$ brine had the best recovery efficiency. However, the $5000 \mathrm{ppm} \mathrm{Cl}$ brine showed significant results. The proposed mechanism can also be adopted here but in this case, the stepwise replacement as seen in the $\mathrm{SO}_{4}$ as shown in Eqs. (6) and (7) is not prominent. Therefore, the repulsion created in Eq. (6) in $\mathrm{SO}_{4}$ mechanism is absent and the promotion of $\mathrm{Ca}^{2+}$ desorption is muted in the $\mathrm{Cl}$ scenario (Eq. 8). So, the better recovery here is attributed to other displacement mechanisms. Furthermore, $5000 \mathrm{ppm}$ $\mathrm{Cl}$ brine produced significant oil recovery compared to the distilled water as opposed to the assumption that $\mathrm{Na}^{+}$and $\mathrm{Cl}^{-}$and other monovalent do not have any wettability altering properties (Darvish Sarvestani et al. 2019).

Apart from the $\mathrm{SO}_{4}$ mechanism proposed in this work, it has been proven that the lower the $\mathrm{Ca}^{2+}$ concentration in the connate water, the greater the effects of low-salinity water (Al-Saedi et al. 2019b). High concentration of $\mathrm{Ca}^{2+}$ in the thin brine film between the rock mineral and the oil leads to less negative surface charges by decreasing the electrostatic repulsive forces between the oil and the rock and increasing the cation bridging which exists between them, ultimately increasing the adhesive forces of the oil onto the rock surface and eventually increasing the oleophilic nature of the rock. In Table 5, the divalent cation $\left(\mathrm{Ca}^{2+}\right)$ count in the high-salinity $\mathrm{SO}_{4}(70,000)$ brine formulation is lower compared to the $\mathrm{Cl}$ brine formulation. This further explains the better recovery seen in low-salinity $\mathrm{SO}_{4}$ flooding over the $\mathrm{Cl}$ scenario.

MIE is a mechanism triggered by the expansion of double layer of the high concentration film between the oil and the rock during LSF (Lee et al. 2010; Katende and Sagala 2019). When low-salinity water is injected into the reservoir, the double layer tends to expand and opens the diffuse layer and electrostatic repulsion between the rock minerals and the oil. Eventually, the repulsive forces exceed the binding forces formed by the multicomponent cation bridges and the oil desorbs from the rock surface. In a study by Lee et al. (2010), they highlighted the roles of divalent cations $\left(\mathrm{Mg}^{2+}\right.$ and $\mathrm{Ca}^{2+}$ ) in the electric double-layer expansion during LSF and from their results, it was clear that $\mathrm{SO}_{4}$-based brines presented larger thicknesses of water layer when comparing (apples to apples) the salts of the monovalent cations at $0.001 \mathrm{M}$ concentration. This supports the results obtained in this work as more oil was recovered in the $\mathrm{SO}_{4}$-based flooding than the $\mathrm{Cl}$ counterpart.

\section{pH evaluation}

Interestingly, the variation of $\mathrm{pH}$ of injected brine and the effluent conforms to the postulates made and drawn out in this work. Figure 15 shows the $\mathrm{pH}$ of the brines before and after flooding. As expected, the high-salinity and distilled water runs showed no apparent change in the $\mathrm{pH}$ values. Reasons are provided in Sect. 3.1.1 where it was stated that

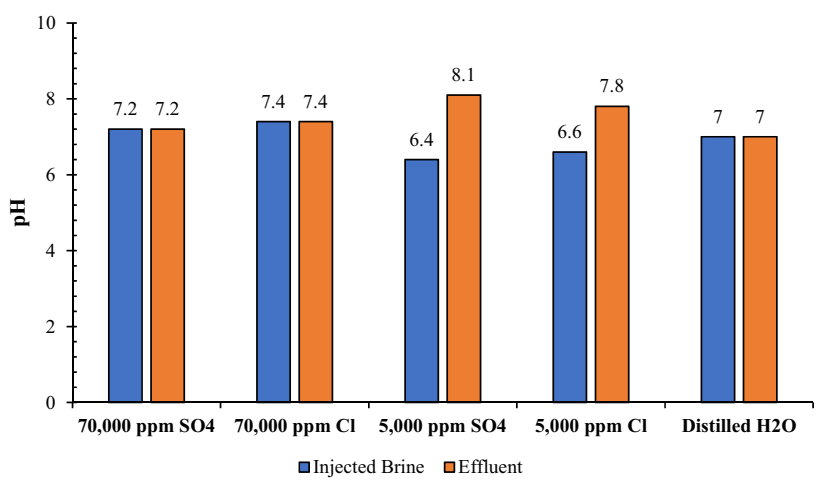

Fig. $15 \mathrm{pH}$ profiles of injected brines and their corresponding effluents

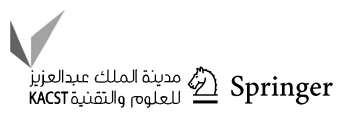




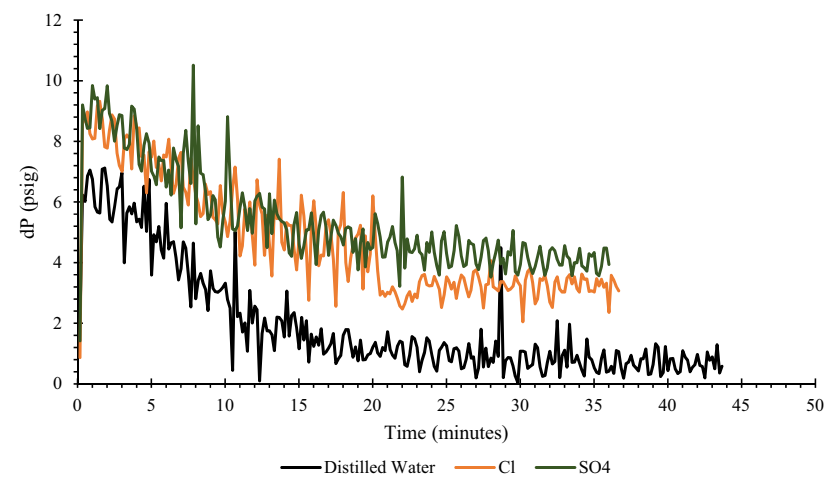

Fig. $16 \mathrm{dP}$ fluctuation of different brine injection scenarios for flow behaviour investigation

there were no interactions between the rock and the injected brines and thus, no expansion in the electric double layer given that the high-salinity brines are of the same order of magnitude in terms of concentration as the connate water. As for the distilled water, there was poor microscopic sweep in terms of recovery shown in Fig. 12 and poor macroscopic sweep, as seen in Fig. 16 in terms flow behaviour of the flooding scenario where the distilled water bypassed the oil characterised by the lower $\mathrm{dP}$ trend. Distilled water bypassed the oil and exited at the end of the core sample easily as seen in Fig. 13 compared to the other brine runs. This finding also reiterates the significance of the presence of ions in the displacement brine during any flooding process.

There was an increase in $\mathrm{pH}$ of 1.8 and 1.2 units when $5000 \mathrm{ppm} \mathrm{SO}_{4}$ and $5000 \mathrm{ppm} \mathrm{Cl}$ brines were used as displacing fluids, respectively. This increase was as a result of the MIE leading to the desorption of $\mathrm{Ca}^{2+}$ and the protonation rock surface. The aqueous solution injected into the core plugs dissociates and the $\mathrm{H}^{+}$finds its way into the rock surface and displaces the $\mathrm{Ca}^{2+}$ present on the rock surface according to the equation:

Clay $-\mathrm{Ca}^{2+}+\mathrm{H}_{2} \mathrm{O} \leftrightarrow$ Clay $-\mathrm{H}^{+}+\mathrm{Ca}^{2+}+\mathrm{OH}^{-}$

Because of the abundance of the $\mathrm{OH}^{-}$, the $\mathrm{pH}$ of the effluent increases after the flooding process. This increase in $\mathrm{pH}$ was accompanied by the better recovery in the $5000 \mathrm{ppm}$ $\mathrm{SO}_{4}$ brine compared to $\mathrm{Cl}$, i.e. there was more desorption of $\mathrm{Ca}^{2+}$ from the rock surface. This desorption implies that breaching of the cation bridge in the $\mathrm{SO}_{4}$ flooding was evident.

$\mathrm{pH}$ was found to play a vital role in the site density of oil/brine. Pooryousefy et al. (2018) observed that the site density of the carbonyl group of the crude oil decreases with increase in $\mathrm{pH}$. In the presence of aqueous ionic solutions, the variation of the site density of the surface chemical groups alters the interfacial tensions (IFT) between the brine and oil. This is yet another suspected mechanism in this work and for that, the interfacial tension measurement is discussed next.

\section{Interfacial tension reduction}

As one of the mechanisms of displacement in LSF, it is important to investigate the precedence of the possible IFT reduction between the injected brine and the oil in the core sample in this study. One of the reasons that prompted this investigation was as a result of the flow behaviour of the injected brine during the core flooding. The dP fluctuation in all the runs presented a characteristic trend with regards the stability of the flow. An exemplar of this is shown in Fig. 16 which showcased a comparison between the flow behaviour of low-salinity injection scenario and distilled water. From the figure, it can be seen that the spiking in the $\mathrm{dP}$ plot of $\mathrm{Cl}$ and distilled water scenarios were significantly more intense than the $\mathrm{SO}_{4}$-based scenario. This is indicative of the fact that in the $\mathrm{SO}_{4}$ runs, the fluids (brine and oil) moved as a single or near homogenous unit compared to the other two runs, with distilled water having the most unstable fluctuations and spiking. The much smoother flow of the $\mathrm{SO}_{4}$ can be explained by either the salting-in effect mechanism (Rezaeidoust et al. 2009) or the emulsification of the oil and brines (Darvish Sarvestani et al. 2019) during the displacement which are all defined by the IFT between the two fluids. Upon physical inspection of the effluents, the oil in water emulsion showed larger oil droplets in the brine and distinct layer between their interface in $\mathrm{Cl}$-based brines. However, for the $\mathrm{SO}_{4}$-based brine effluents, there was no distinct later between the brine and oil and the emulsion showed smaller droplets of oil and upon standing (after $24 \mathrm{~h}$ ), the oil droplets coalesced and became larger droplets. It is a form of oil in water emulsion which will not pose flow assurance problems during production. The surface interactions between these fluids are responsible for such phenomena. Using the set-up described in the experimental section, the IFT between the oil and different brines was measured at $50{ }^{\circ} \mathrm{C}$ and 1500 psig. The results are tabulated and shown below:

Accordingly, these results explain flow behaviour observed during the displacement process. Darvish Sarvestani et al. (2019) explained that decreasing the salts in the brine would result in higher stability of the formed emulsion droplets by lowering the rate of coalescence and aggregation thereby improving the mobility of the oil and water and, hence improving recovery. This centres around the surface energies of the fluids in contact as can be seen from the results in Table 6. These results are consistent with the trends observed in the works of Khaksar Manshad et al. (2016) where it was clear that the IFT between the oil and $\mathrm{SO}_{4}$ brines is significantly lower than those of 
Table 6 IFT results of all brines at $1500 \mathrm{psig}$ and $50{ }^{\circ} \mathrm{C}$

\begin{tabular}{lll}
\hline Brine types & IFT $(\mathrm{mN} / \mathrm{m})$ & $\begin{array}{l}\text { Standard } \\
\text { deviation } \\
(\mathrm{mN} / \mathrm{m})\end{array}$ \\
\hline Distilled H $\mathrm{H}_{2} \mathrm{O}$ & 51.74 & 0.19 \\
$70,000 \mathrm{ppm} \mathrm{Cl}$ & 47.43 & 0.23 \\
$5000 \mathrm{ppm} \mathrm{Cl}$ & 34.23 & 0.21 \\
$70,000 \mathrm{ppm} \mathrm{SO}_{4}$ & 41.93 & 0.09 \\
$5000 \mathrm{ppm} \mathrm{SO}_{4}$ & 25.04 & 0.14 \\
\hline
\end{tabular}

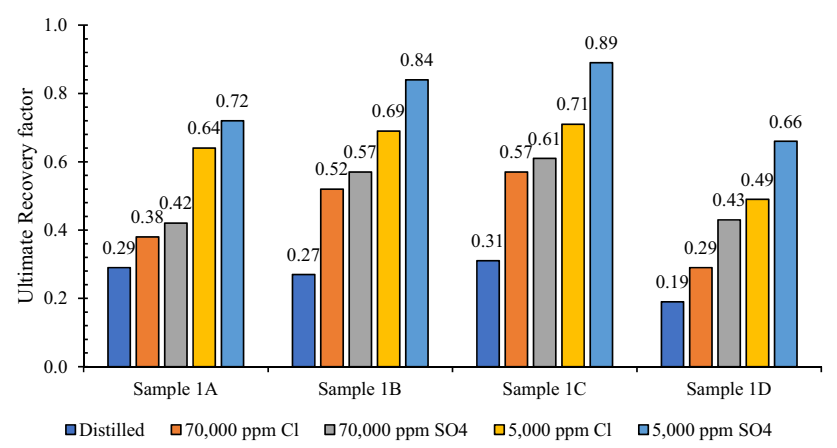

Fig. 17 Ultimate recovery of all experimental runs

Cl-based brines at different conditions (pressures, temperatures and concentrations).

The IFT between the brine and oil is lowest in the $5000 \mathrm{ppm} \mathrm{SO}_{4}$ brine which yielded the most recovery in all the runs combined as shown in Fig. 17. This was followed by the $5000 \mathrm{ppm} \mathrm{Cl}$ with distilled water having the highest IFT; evident with the unstable flow behaviour, early breakthrough, and poor recovery efficiency in a displacement process characterised by oil bypass. This variation of IFT between the brines is due to the accumulation of the cations at the crude oil/brine interface which can be explained by the Gibb's adsorption isotherm as reported by Kakati and Sangwai (2017).

Figure 17 highlights the overall ultimate recovery from all the core samples, and it is clear that the $\mathrm{SO}_{4}$ brines had the best recovery compared to the other brines. Sample 1D had the worst performance amongst the core sample tested, and this can be as a result of the low permeability compared to the other core samples as shown in Table 3. Additionally, distilled water performance is identical in all the runs and overall, low-salinity brines had the best performance already stated in the literature. The increase in $\mathrm{pH}$ in low-salinity brines is highest in $\mathrm{SO}_{4}$ while there were no significant changes in the effluents after the highsalinity and distilled water displacement tests.

\section{Conclusion}

The role of chloride and sulphate-based brines in lowsalinity flooding with a hybrid smart water injection technique was investigated in this study. The results obtained in this study revealed that a combination of sulphate-based brine improved oil recovery to a significant degree as seen in the ultimate recovery results from all the core samples. These conclusions can be drawn from this work:

- Distilled water experiments highlighted the significance of the presence of ions in the displacement brines given the poor microscopic and macroscopic sweeps depicted by the poor recovery efficiencies in all the flooded core plugs albeit the presence of kaolinite clays.

- A pH increase of 1.8 units was realised in the $5000 \mathrm{ppm}$ $\mathrm{SO}_{4}$-based flooding followed by $5000 \mathrm{ppm} \mathrm{Cl}$ with 1.2 units. There were no $\mathrm{pH}$ changes in higher salinity $(70,000)$ and the distilled water runs.

- A possible mechanism where $\mathrm{SO}_{4}$ ion breaks and replaces the carboxyl group at the cation bridge site in low-salinity flooding was postulated which promotes the desorption of the $\mathrm{Ca}^{2+}$ from the rock.

- Low-salinity $\left(\mathrm{SO}_{4}\right)$ brine was observed to possess the lowest IFT $(25.04 \mathrm{mN} / \mathrm{m})$ between the oil and brine and distilled water exhibited the highest IFT of $51.74 \mathrm{mN} / \mathrm{m}$ which may be significant to overcome the capillary pressure of the pore matrix and contribute in altering the wettability of the rock mineral to a more water wet state.

Despite the higher ionic strengths of the $\mathrm{SO}_{4}$ brines, better recoveries were yet obtained compared to the lower ionic strengths of the $\mathrm{Cl}$ counterpart in each brine class. This is as a result of the presence of the $\mathrm{SO}_{4}$ ion and the role it plays in the aiding of wettability alteration, $\mathrm{pH}$ offset, and interfacial tension reduction unlike the Cl-based brines where only the active cations $\left(\mathrm{Ca}^{2+}\right)$ were responsible for the improved recovery. Therefore, a combination of MIE, salting-in effects, IFT reduction, and $\mathrm{pH}$ increase was responsible for the improved recovery by $\mathrm{SO}_{4}$ displacement. Cl-based brines also appeared to have, to an extent, improved recovery capabilities in their own respects. Ionic count, relative permeability, effluent analysis and investigation will be considered in future works for detailed deduction of what was observed in this current study.

Acknowledgements The author would like to express immense gratitude to Kuwait Oil Company for the studentship and also the Petroleum and Spray Research Group of the University of Salford for the consultation. 
Open Access This article is licensed under a Creative Commons Attribution 4.0 International License, which permits use, sharing, adaptation, distribution and reproduction in any medium or format, as long as you give appropriate credit to the original author(s) and the source, provide a link to the Creative Commons licence, and indicate if changes were made. The images or other third party material in this article are included in the article's Creative Commons licence, unless indicated otherwise in a credit line to the material. If material is not included in the article's Creative Commons licence and your intended use is not permitted by statutory regulation or exceeds the permitted use, you will need to obtain permission directly from the copyright holder. To view a copy of this licence, visit http://creativecommons.org/licenses/by/4.0/.

\section{References}

Aladasani A, Bai B, Wu Y (2012) Investigating low-salinity waterflooding recovery mechanisms in sandstone reservoirs. In: Eighteenth SPE improved oil recovery symposium, pp 1-28. https:// doi.org/10.2118/152997-MS

Alameri W, Teklu TW, Graves RM et al (2014) Wettability alteration during low-salinity waterflooding in carbonate reservoir cores. In: SPE Asia Pacific oil gas conference and exhibition, pp 1-18. https ://doi.org/10.2118/171529-MS

Al-Attar HH, Mahmoud MY, Zekri AY et al (2013) Low-salinity flooding in a selected carbonate reservoir: experimental approach. J Pet Explor Prod Technol 3:139-149. https://doi.org/10.1007/s1320 2-013-0052-3

Alotaibi M, Nasralla R, Nasr-El-Din H (2011) Wettability studies using low-salinity water in sandstone reservoirs. SPE Reserv Eval Eng 14:3-6. https://doi.org/10.2118/149942-PA

AlQuraishi AA, AlHussinan SN, AlYami HQ (2015) Efficiency and recovery mechanisms of low salinity water flooding in sandstone and carbonate reservoirs. In: Offshore mediterranean conference and exhibition, OMC 2015. Offshore Mediterranean Conference

Al-Saedi HN, Flori RE, Al-Jaberi SK (2019a) Eliminate the role of clay in sandstone: EOR low salinity water flooding. J Pet Explor Prod Technol 9:1475-1483. https://doi.org/10.1007/s1320 2-018-0548-y

Al-Saedi HN, Flori RE, Brady PV (2019b) Effect of divalent cations in formation water on wettability alteration during low salinity water flooding in sandstone reservoirs: oil recovery analyses, surface reactivity tests, contact angle, and spontaneous imbibition experiments. J Mol Liq 275:163-172. https://doi.org/10.1016/j. molliq.2018.11.093

Aminian A, ZareNezhad B (2019) Wettability alteration in carbonate and sandstone rocks due to low salinity surfactant flooding. J Mol Liq 275:265-280. https://doi.org/10.1016/j.molliq.2018.11.080

Austad T, Rezaeidoust A, Puntervold T (2010) Chemical mechanism of low salinity water flooding in sandstone reservoirs. SPE 129767:19-22. https://doi.org/10.2118/129767-MS

Bartels W-B, Mahani H, Berg S et al (2016) Low salinity flooding LSF in sandstones at pore scale: micro-model development and investigation. In: Proceedings of SPE annual technical conference and exhibition

Bedrikovetsky P, Zeinijahrami A (2015) Case study of low salinity water injection in Zichebashskoe field. J Pet Sci Res 4:16-31. https://doi.org/10.12783/jpsr.2015.0401.03

Berg S, Cense AW, Jansen E, Bakker K (2010) Direct experimental evidence of wettability modification by low salinity. Petrophysics 51:314-322. https://doi.org/10.1179/095066059790421773

Chen Y, Xie Q, Pu W, Saeedi A (2018) Drivers of pH increase and implications for low salinity effect in sandstone. Fuel 218:112 117. https://doi.org/10.1016/j.fuel.2018.01.037
Cissokho M, Boussour S, Cordier P, Bertin H, Hamon G (2010) Low salinity oil recovery on clayey sandstone: experimental study. Petrophysics 51(5):305-313

Darvish Sarvestani A, Ayatollahi S, Bahari Moghaddam M (2019) Smart water flooding performance in carbonate reservoirs: an experimental approach for tertiary oil recovery. J Pet Explor Prod Technol. https://doi.org/10.1007/s13202-019-0650-9

Ding H, Rahman S (2017) Experimental and theoretical study of wettability alteration during low salinity water flooding-an state of the art review. Colloids Surf A Physicochem Eng Asp. https://doi. org/10.1016/j.colsurfa.2017.02.006

Fjelde I, Asen SM, Omekeh A (2012) Low salinity water flooding experiments and interpretation by simulations. In: Eighteenth SPE improved oil recovery symposium held Tulsa, pp 1-12. https://doi. org/10.2118/154142-MS

Fredriksen SB, Rognmo AU, Fernø MA (2016) Pore-scale mechanisms during low salinity waterflooding: water diffusion and osmosis for oil mobilization. https://doi.org/10.2118/180060-MS

Fredriksen SB, Rognmo AU, Sandengen K, Fernø MA (2017) Wettability effects on osmosis as an oil-mobilization mechanism during low-salinity. Petrophysics 58:28-35

Hamouda AA, Valderhaug OM, Munaev R, Stangeland H (2014) Possible mechanisms for oil recovery from chalk and sandstone rocks by low salinity water (LSW). In: SPE improved oil recovery symposium, pp 1-13. https://doi.org/10.2118/169885-MS

Kakati A, Sangwai JS (2017) Effect of monovalent and divalent salts on the interfacial tension of pure hydrocarbon-brine systems relevant for low salinity water flooding. J Pet Sci Eng 157:1106-1114. https://doi.org/10.1016/j.petrol.2017.08.017

Katende A, Sagala F (2019) A critical review of low salinity water flooding: mechanism, laboratory and field application. J Mol Liq 278:627-649. https://doi.org/10.1016/j.molliq.2019.01.037

Khaksar Manshad A, Olad M, Taghipour SA et al (2016) Effects of water soluble ions on interfacial tension (IFT) between oil and brine in smart and carbonated smart water injection process in oil reservoirs. J Mol Liq 223:987-993. https://doi.org/10.1016/j. molliq.2016.08.089

Kumar M, Fogden A, Morrow NR, Buckley JS (2011) Mechanisms of improved oil recovery from sandstone by low salinity flooding. Petrophysics 52(6):428-436

Kumar HT, Shehata AM, Nasr-El-Din HA (2016) Effectiveness of lowsalinity and $\mathrm{CO}_{2}$ flooding hybrid approaches in low-permeability sandstone reservoirs. In: Society of petroleum engineers-SPE trinidad and tobago section energy resources conference. Society of Petroleum Engineers. https://doi.org/10.2118/180875-MS

Lager A, Webb KJ, Black CJJ et al (2008) Low salinity oil recoveryan experimental investigation 1. Petrophysics 49:28-35

Lee SY, Webb KJ, Collins IR et al (2010) Low salinity oil recoveryincreasing understanding of the underlying mechanisms. In: SPEDOE improved oil recovery symposium proceedings, vol 1, pp 534-544

Mahani H, Berg S, Ilic D et al (2015) Kinetics of low-salinity-flooding effect. SPE J 20:8-20. https://doi.org/10.2118/165255-PA

Mcguire PLL, Chatham JRR, Paskvan FKK et al (2005) Low salinity oil recovery: an exciting new EOR opportunity for Alaska's North Slope. SPE West regional meeting, pp 1-15. https://doi. org/10.2118/93903-MS

Moustafa EAAA, Shedid SA (2018) Effects of magnesium and potassium sulfates on oil recovery by water flooding. Egypt J Pet 27:649-656. https://doi.org/10.1016/j.ejpe.2017.09.007

Nasralla R, Nasr-El-Din H (2011) Coreflood study of low salinity water injection in sandstone reservoirs. In: Proceeding of SPE/ DGS Saudi Arabia section technical symposium and exhibition, pp 15-18. https://doi.org/10.2118/149077-MS

Nasralla RA, Nasr-el-din HA (2012) Double-layer expansion: is it a primary mechanism of improved oil recovery by low-salinity 
waterflooding? In: Eighteenth SPE improved oil recovery symposium, pp 1-17. https://doi.org/10.2118/154334-MS

Nasralla RA, Alotaibi MB, Nasr-El-Din HA (2011) Efficiency of oil recovery by low salinity water flooding in sandstone reservoirs. SPE West North American regional meeting. https://doi. org/10.2118/144602-MS

Nasralla RA, Bataweel MA, Nasr-El-Din HA (2013) Investigation of wettability alteration and oil-recovery improvement by lowsalinity water in sandstone rock. J Can Pet Technol 52:144-154. https://doi.org/10.2118/146322-PA

Pooryousefy E, Xie Q, Chen Y et al (2018) Drivers of low salinity effect in sandstone reservoirs. J Mol Liq 250:396-403. https:// doi.org/10.1016/j.molliq.2017.11.170

Qiao C, Johns R, Li L (2016) Understanding the chemical mechanisms for low salinity waterflooding. In: 78th EAGE conference and exhibition 2016: efficient use of technology-unlocking potential. European Association of Geoscientists and Engineers, EAGE. https://doi.org/10.2118/180138-ms

Rezaei Gomari S, Joseph N (2017) Study of the effect of clay particles on low salinity water injection in sandstone reservoirs. Energies 10:322. https://doi.org/10.3390/en10030322

Rezaeidoust A, Puntervold T, Strand S, Austad T (2009) Smart water as wettability modifier in carbonate and sandstone: a discussion of similarities/differences in the chemical mechanisms. Energy Fuels 23:4479-4485. https://doi.org/10.1021/ef900185q

Robertson EP (2007) Low-Salinity Waterflooding to Improve Oil Recovery-Historical Field Evidence. In: SPE annual technical conference and exhibition. https://doi.org/10.2118/109965-MS

Schlumberger (2017) Low-salinity waterflooding. http://www.glossary. oilfield.slb.com/Terms/l/low-salinity_waterflooding.aspx? $\mathrm{p}=1$. Accessed 22 May 2017

Shabib-Asl A, Ayoub MA, Elraies K. (2015) Laboratory investigation into wettability alteration by different low salinity water compositions in sandstone rock. In: SPE/IATMI Asia Pacific oil gas conference and exhibition. https://doi.org/10.2118/176492-MS

Sheng JJ (2014) Critical review of low-salinity waterflooding. J Pet Sci Eng 120:216-224. https://doi.org/10.1016/j.petrol.2014.05.026

Shiran BS, Skauge A (2012) Wettabilitty and oil recovery by low salinity injection. SPE, p 1556. https://doi.org/10.2118/155651-MS
Sino Australia Oil \& Gas Pty Limited (2013) An introduction to enhanced oil recovery techniques, p 6. https://www.mendeley. com/catalogue/82051636-f756-351e-b773-936dd7b24f21/?utm source $=$ desktop\&utm_medium $=1.19 .4 \& u t m \_$campaign $=$open catalog\&userDocumentId=\%7Bec7b5406-7f5c-4444-801b-3b03a 7f24d74\%7D

Sohrabi M, Mahzari P, Farzaneh SA et al (2015) Novel insights into mechanisms of oil recovery by low salinity water injection. SPE

Sorbie KS, Collins IR (2010) A proposed pore-scale mechanism for how low salinity waterflooding Works. "SPE 129833 " paper present SPE improved oil recovery symposium 24-28 April Tulsa, Oklahoma, USA, pp 1-18. https://doi.org/10.2118/129833-MS

Suman YK, Shirif E, Ibrahim H, Ala-Ktiwi A (2014) Evaluation of low saline "smart water" enhanced oil recovery in light oil reservoirs. World J Eng Technol 2(1):13-22. https://doi.org/10.4236/ wjet.2014.21002

Tang GQ, Morrow NR (1999) Influence of brine composition and fines migration on crude oil/brine/rock interactions and oil recovery. J Pet Sci Eng 24:99-111. https://doi.org/10.1016/S0920 -4105(99)00034-0

Vledder P, Gonzalez I, Carrera Fonseca J et al (2010) Low salinity water flooding: proof of wettability alteration on a field wide scale. In: Proceedings of SPE improved oil recovery symposium, pp 1-10. https://doi.org/10.2118/129564-MS

Yang J, Dong Z, Dong M et al (2016) Wettability alteration during low-salinity waterflooding and the relevance of divalent ions in this process. Energy Fuels 30:72-79. https://doi.org/10.1021/acs. energyfuels. $5 \mathrm{~b} 01847$

Yousef AA, Al-Saleh S, Al-Kaabi A, Al-Jawfi M (2010) Laboratory investigation of novel oil recovery method for carbonate reservoirs. In: Society of Petrolium Engineers-Canadian unconventional resources and international petroleum conference 2010, vol 3, pp 1825-1859. https://doi.org/10.2118/137634-ms

Publisher's Note Springer Nature remains neutral with regard to jurisdictional claims in published maps and institutional affiliations. 